\title{
Impedance Method Used To Calculate Initial Switching Currents in Transmission Networks and Generator Real Power
}

\author{
Jan Machowski, Piotr Kacejko, Piotr Miller
}

\begin{abstract}
Switching-on of transmission network elements can bring about high inrush currents in the network elements (lines and transformers) as well as sudden changes in real power of generating units. In order to reduce those disadvantageous effects in modern power systems switching operations are controlled by protection devices referred to as synchro-check. Optimal setting of the synchro-check parameters requires the application of adequate criteria and an efficient method for calculating current changes in lines and generators that result from switching operations. This article proposes a new calculation method based on a nodal impedance matrix. Such a matrix is commonly used for short-circuit analyses. The advantage of the proposed method is that a short-circuit software with an adequate extension can be also applied to the analysis of switching operations.
\end{abstract}

Keywords - initial switching current, switching operations, synchro-check

\section{INTRODUCTION}

$S^{*}$ witching-on operations performed on transmission network elements (lines and transformers) can be classified into (a) synchronous and (b) asynchronous ones.

In the synchronous case, a given network element gets switched in a synchronously operating transmission network. Transmission networks are characterized by a meshed structure. When a given element gets switched in a meshed network, new meshes get formed and sudden changes in current flows are forced. At the first instant following switching-on of the network element an electromagnetic transient state occurs and it is characterized by high inrush currents as well as sudden changes in real power of generating units. That electromagnetic transient state of the approximately 1-second duration [1] leads to a new steady state. Synchronous switching operations can involve the following hazardous phenomena [2]:

C1. Dynamic damage of a circuit breaker that can occur when the rated switching capability gets exceeded [3].

C2. Unwanted operation of distance protection and automatic switching-off of a given network element right after its switching-on [4].

C3. Deformation of transformer windings and/or generator end-windings that occurs due to the action of forces caused by high inrush current [5]. The ability of transformers to withstand the dynamic effect of currents is designed for short-circuits at the transformer terminals.

C4. Torsional oscillations and fatigue of generating unit shafts that can cause considerable shortening of their life time [6-13].

In the asynchronous switching cases, a transmission line gets switched in the asynchronously operating subsystem transmission network. In such a condition the above mentioned hazards also occur but the occurrence of a new steady-state follows the electromagnetic transient state whose duration is of a dozen of seconds. That state is manifested by swings of generator rotors and the accompanying power swings in the transmission network [14]. Additional hazard can consist in the:

C5. potential occurrence of unsuccessful synchronization of the both subsystems (loss of transient stability of the power system).

If the transient stability conditions are met a new equilibrium state is determined by the power system steady-state characteristics that correspond to the primary load and frequency control [14].

In order to limit the above mentioned hazards, all modern power systems are equipped with protection devices that check switching operations in transmission networks. The devices are referred to as synchro-check relays [15-20]. Their setting parameters refer to the following quantities across both poles of a circuit breaker:

(a) differences in the voltage magnitudes,

(b) differences in phase angles (closing angle),

(c) frequency slip.

As far as the parameters are concerned, pertinent publications give setting values that considerably differ among one another. The biggest differences that can be found in recommendations comprised in that literature concern the closing angle threshold value. It is shown in Table 1. As can be seen, distribution of the recommended values is considerable and it ranges from $20^{\circ}$ to $60^{\circ}$.

Settings of the synchro-check devices should be optimized so that the maximal use of the designed capacity is obtained without posing any hazard for the equipment safety. The application of threshold values that are too low can cause difficulties in performing switching operations, when they should be performed from the viewpoint of the power system security.

TABLE 1 
MAXIMAL VALUES OF THE CLOSING ANGLE RECOMMENDED IN THE LITERATURE

\begin{tabular}{|c|c|c|}
\hline \multirow[b]{2}{*}{ Reference } & \multicolumn{2}{|l|}{. } \\
\hline & $\begin{array}{l}\text { Max closing } \\
\text { angle }\end{array}$ & Recommendation \\
\hline [16] & $(20 \div 30)^{\circ}$ & - \\
\hline \multirow[b]{2}{*}{ [17] } & $60^{\circ}$ & $\begin{array}{c}\text { For lines that are electrically far from } \\
\text { generating stations. }\end{array}$ \\
\hline & $<60^{\circ}$ & $\begin{array}{l}\text { For lines that are electrically close to } \\
\text { generating stations, the threshold value } \\
\text { should be determined with regard to the } \\
\text { detailed shaft torque considerations. }\end{array}$ \\
\hline \multirow{3}{*}[18,21]{} & $(20 \div 30)^{\circ}$ & For $(400 \div 500) \mathrm{kV}$ \\
\hline & $(30 \div 40)^{\mathrm{o}}$ & For $230 \mathrm{kV}$ \\
\hline & $(50 \div 60)^{\mathrm{o}}$ & For $132 \mathrm{kV}$ \\
\hline \multirow{2}{*}{ [22] } & $60^{\circ}$ & $\begin{array}{c}\text { For lines that are electrically far from } \\
\text { generating stations. }\end{array}$ \\
\hline & $20^{\circ}$ & $\begin{array}{c}\text { For lines that are electrically close to } \\
\text { generating stations. }\end{array}$ \\
\hline
\end{tabular}

The blackout described in [23] makes a good example of such a situation. The whole North-South corridor, from Northern Europe to Italy, was overloaded, which caused cascade tripping of many transmission lines and finally a blackout over a large part of the European power system. During the initial emergency state, a network operator of one of the subsystems tried to reduce the overload by switching-on a transmission line. However, the switching operation was blocked by a synchro-check device, because its setting was of $30^{\circ}$, while the switching angle on that line in the emergency state was $42^{\circ}$. Higher setting of this synchro-check device (for example at $45^{\circ}$ ) could possibly change the situation. That event has given rise to intensive studies on the optimization of all synchrocheck settings [16].

In $[18,21,22]$ it has also been emphasized that, when threshold values of the synchro-check settings are too low, power system restoration in hard-loading conditions can be difficult, because the standing phase angle reduction usually requires rescheduling of real power outputs in a number of power plants.

The presented paper proposes a new method together with a computer software for fast calculations of all quantities that are indispensable for the selection of threshold values for synchro-check devices.

\section{THE PROPOSED METHOD}

On the basis of the above mentioned $\mathrm{C} 1-\mathrm{C} 4$ hazards the following criteria can be accepted as the criteria for the allowed switching-on conditions as well as for the selection of synchro-check setting parameters:

C1. The rated peak withstand current $i_{\mathrm{B}}$ must be larger than the switching current peak value $i_{\mathrm{p}}$ that is: $\sqrt{2} k I_{0+}<i_{\mathrm{B}}$, where $k \leq 2$ is the peak factor, $I_{0+}$ is the RMS value of the current at the closing instant $t=0_{+}$.

C2. The apparent impedance measured by distance relay $\underline{Z}=\underline{V}_{0+} / \underline{I}_{0+}$ at the closing instant must be outside of the distance protection fault detector zone.

C3. The initial switching current cannot exceed the initial value of any short-circuit current at the transformer terminals, that is: $I_{0+} £ I_{\mathrm{K} 3}$ where $I_{\mathrm{K} 3}$ is the 3-phase short-circuit current.

C4. Switching operations do not present any hazard for the safety of a large generating unit $[5,13]$ if the change in the real power (caused by the switching) is smaller than $50 \%$ of the power rating, i.e.

$\Delta P_{\mathrm{G} 0+}=\operatorname{Re}\left(\underline{E}_{\mathrm{G}}^{\prime \prime} \cdot \Delta \underline{I}_{\mathrm{G} 0+}^{*}\right) \leq 0.5 P_{\mathrm{Gr}}$ where the subscript $\mathrm{G}$ refers to a given generator.

The above given description of those criteria indicates that they can be verified without performing simulation of the fast transient phenomena caused by switching operations in the power system. In order to check the criteria it is enough to calculate:

(1) the initial switching current $I_{0+}$ understood as the effective value of the current at the first moment $t=0_{+}$ after the circuit breaker gets closed,

(2) the change in its real power of all generators $\mathrm{D} P_{\mathrm{G} 0+}$ caused by closing the circuit breaker.

The presented article proposes a new method for calculating the mentioned quantities. The method is based on a nodal impedance matrix. Its advantage is that a short-circuit program (that is widely available at transmission system operators) can be applied to elaborate the adequate computer software.

\section{A. Assumptions}

A network model to be used for calculating initial switching currents is shown in Figure 1. Set $\{B\}$ includes generation buses, while set $\{\mathrm{G}\}$ comprises fictitious nodes behind the generator impedances and their step-up transformers. Set $\{\mathrm{L}\}$ is a set of load nodes. Loads are replaced by constant admittances. Nodes a,b are poles of a circuit breaker that gets switched on. Voltages across the circuit breaker poles are denoted by $\underline{V}_{\mathrm{a}}, \underline{V}_{\mathrm{b}}$ and $\underline{V}_{\mathrm{ab}}=\left(\underline{V}_{\mathrm{a}}-\underline{V}_{\mathrm{b}}\right)$, respectively. Difference of the voltage phasor angles is denoted by $\theta_{\mathrm{ab}}$, as in Figure $1 b$.

Similarly as in the case of calculating initial short-circuit currents [19], for the initial switching current calculations synchronous generators should be represented as for the subtransient state [14], that is with the application of subtransient electromotive forces $\underline{E}^{\prime \prime}$ behind subtransient reactances at the assumption that $X_{\mathrm{q}}^{\prime \prime} @ X_{\mathrm{d}}^{\prime \prime}$. a)

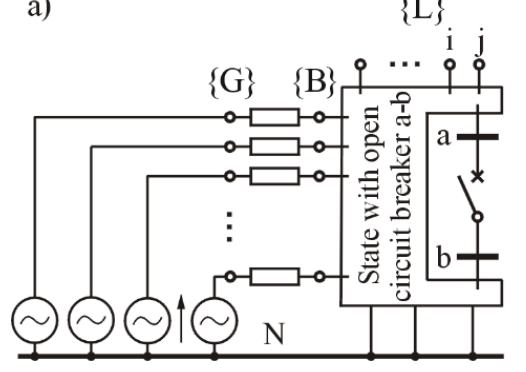

b)

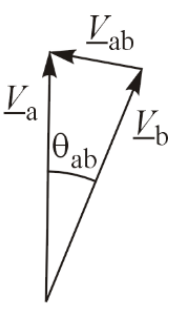

Figure 1 Illustration of the mathematical network model

Subtransient electromotive forces $\underline{E}$ " should be calculated for the preset loading conditions in the power system. They make voltage sources in the transmission network model (Figure 1). 


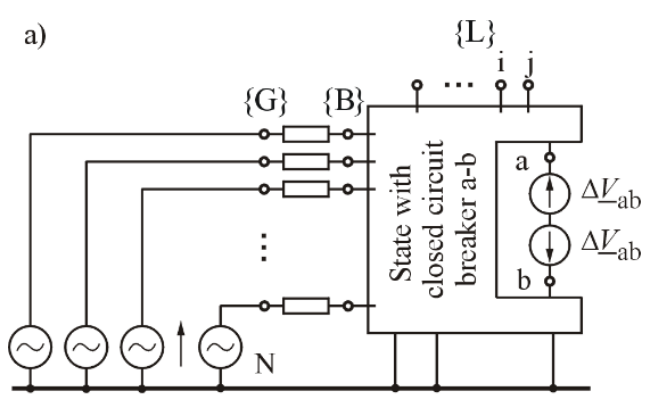

b)

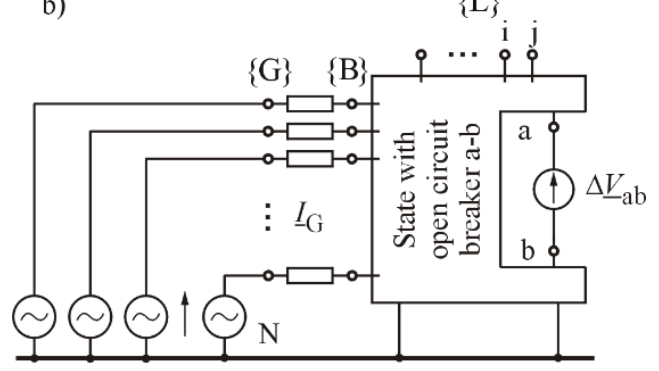

c)

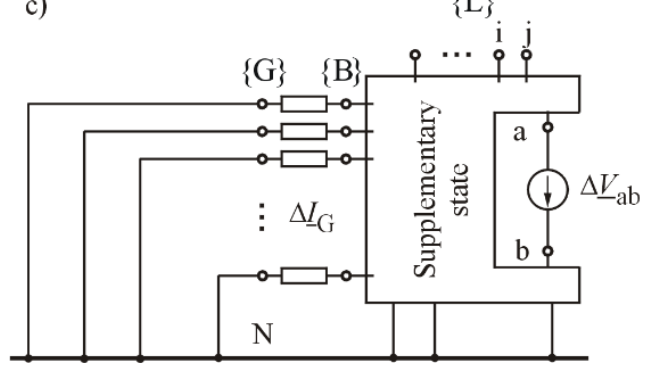

Figure 2 Application of the superposition method for the closed circuit breaker state

\section{B. Application of the superposition method}

When a circuit breaker is closed, there is no voltage difference between its terminal nodes a,b. The zero voltage value across the poles can be replaced by two voltage sources $\underline{V}_{\text {ab }}$ of the opposite orientation (Figure 2a). The value $\underline{V}_{\mathrm{ab}}$ is selected so that it corresponds to the voltage difference across the circuit breaker poles right before its closing, that is for the instant $t=0_{-}$. As the discussed network is linear, then, according to the superposition principle, it can be divided into two networks presented in Figure $2 b$ and Figure $2 c$, respectively.

The network shown in Figure $2 b$ corresponds to the condition before the circuit breaker gets closed i.e. when it is still open. In this state generators are loaded with currents $\underline{\mathbf{I}}_{\mathrm{G}}$ and there are voltages $\underline{V}_{i}$ and $\underline{V}_{j}$ at the arbitrary nodes $i, j$, respectively.

Supplementary network shown in Figure $2 \mathrm{c}$ is a fictitious network that corresponds to the difference between the closed and open states of a circuit breaker. That fictitious network is a passive network supplied from one voltage source $\underline{V}_{\text {ab }}$. This network is very useful for the discussed calculations as it includes all the searched quantities: current $\underline{I}_{\mathrm{ab}}=\underline{I}_{0+}$ that corresponds to the initial switching current flows through the $\underline{\underline{a b}}_{\mathrm{ab}}$ source (Figure 2c),

currents $\mathrm{D}_{\underline{\mathrm{I}}_{\mathrm{G}}}=\mathrm{D} \underline{\mathbf{I}}_{\mathrm{G} 0+}$ that correspond to the changes in generator currents caused by closing of a circuit breaker, flow through the generator branches (Figure 2c).

The discussed network (Figure 2c) is a fictitious network, where nodal voltages correspond to the difference of the voltages of the closed-breaker state and the voltages of the open-breaker state. In arbitrary $i, j$ nodes there are voltages $\left(\underline{V}_{i}^{+}-\underline{V}_{i}\right)$ and $\left(\underline{V}_{j}^{+}-\underline{V}_{j}\right)$, respectively. The superscript + corresponds to the state after the circuit breaker gets closed. Voltages $\left(\underline{\mathbf{V}}_{\mathrm{G}}^{+}-\underline{\mathbf{V}}_{\mathrm{G}}\right)$ are present at the $\{\mathrm{S}\}$ nodes, where to generating units are connected.

\section{Nodal impedance equation}

It follows from the above considerations that the network shown in Figure $2 \mathrm{c}$ can be used to determine changes in generator currents $\left(\Delta \underline{\boldsymbol{I}}_{\mathrm{G}}\right)$ caused by the circuit breaker closing. For that purpose, the voltage source $\underline{V}_{\mathrm{ab}}$ of Figure 2c is replaced by two nodal currents $+\underline{I}_{\mathrm{ab}}$ and $-\underline{I}_{\mathrm{ab}}$, as shown in Figure 3.

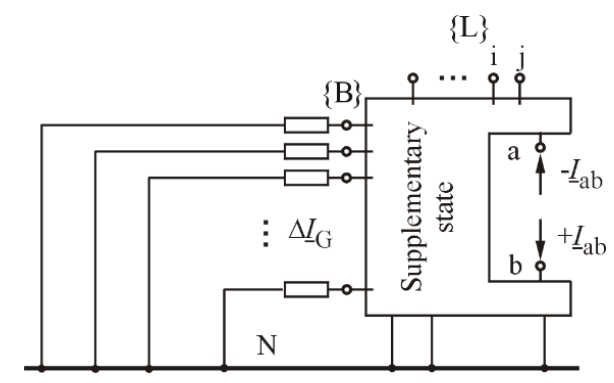

Figure 3 Illustration of the impedance method

The network shown in Figure 3 can be described by the following nodal matrix equation:

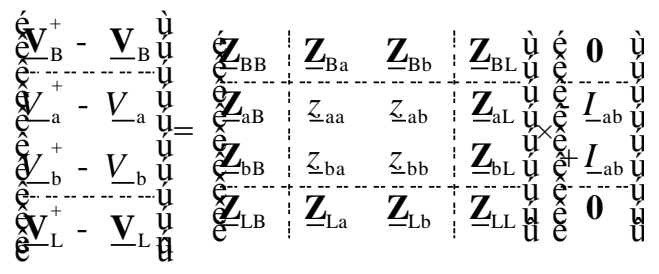

where the nodal impedance matrix is an inverted nodal admittance matrix. Subscripts B,a,b,L correspond to the nodes $\{B\}, a, b,\{L\}$, respectively. It needs to keep in mind that all the voltage and current values are complex numbers and have to be given within a common reference frame. Nodal currents occur only in the nodes a,b that correspond to the circuit breaker poles.

As nodal currents of the $\{\mathrm{B}\}$ and $\{\mathrm{L}\}$ nodes are zero valued, in Equation (1) only a part of the impedance matrix is important. For the a,b nodes the following equation can be written: 
$\left[\begin{array}{l}\underline{V}_{\mathrm{a}}^{+}-\underline{V}_{\mathrm{a}} \\ \underline{V}_{\mathrm{b}}^{+}-\underline{V}_{\mathrm{b}}\end{array}\right]=\left[\begin{array}{ll}\underline{z}_{\mathrm{aa}} & \underline{z}_{\mathrm{ab}} \\ \underline{z}_{\mathrm{ba}} & \underline{z}_{\mathrm{bb}}\end{array}\right] \cdot\left[\begin{array}{l}-\underline{I}_{\mathrm{ab}} \\ +\underline{I}_{\mathrm{ab}}\end{array}\right]$

This matrix equation corresponds to the following two scalar equations:

$\underline{V}_{\mathrm{a}}^{+}-\underline{V}_{\mathrm{a}}=-\underline{z}_{\mathrm{aa}} \underline{I}_{\mathrm{ab}}+\underline{z}_{\mathrm{ab}} \underline{I}_{\mathrm{ab}}$

$\underline{V}_{\mathrm{b}}^{+}-\underline{V}_{\mathrm{b}}=-\underline{z}_{\mathrm{ba}} \underline{I}_{\mathrm{ab}}+\underline{z}_{\mathrm{bb}} \underline{I}_{\mathrm{ab}}$

For the closed-breaker state it appears that $\underline{V}_{\mathrm{b}}^{+}=\underline{V}_{\mathrm{a}}^{+}$, because there is no voltage difference at the closed circuit breaker. Considering and assuming that $\underline{z}_{\mathrm{ab}}=\underline{z}_{\mathrm{ba}}$, after having performed both-sides subtraction of Equation (3a) from Equation (3b), the following can be obtained:

$\underline{V}_{\mathrm{ab}}=\underline{V}_{\mathrm{a}}-\underline{V}_{\mathrm{b}}=\left(\underline{z}_{\mathrm{aa}}+\underline{z}_{\mathrm{bb}}-2 \cdot \underline{z}_{\mathrm{ab}}\right) \cdot \underline{I}_{\mathrm{ab}}$

Hence, the initial switching current is given by the following equation:

$\underline{I}_{\mathrm{ab}}=\frac{\underline{V}_{\mathrm{ab}}}{\underline{z}_{\mathrm{aa}}+\underline{z}_{\mathrm{bb}}-2 \cdot \underline{z}_{\mathrm{ab}}}$

where: $\underline{V}_{\mathrm{ab}}$ is the voltage across the circuit breaker poles, before the breaker gets closed, $\underline{z}_{\mathrm{aa}}, \underline{z}_{\mathrm{bb}}, \underline{z}_{\mathrm{ab}}$ are the elements of the nodal impedance matrix.

\section{D. $\pi$-equivalent model}

Equation (2) fully describes the whole network seen by the nodes $a, b$ that correspond to the circuit breaker poles. Thus, it can be stated that the network model reduced to the nodes $a, b$ can be described by the following nodal admittance matrix:

$\underline{\boldsymbol{Y}}_{\pi}=\left[\begin{array}{ll}\underline{y}_{\mathrm{aa}} & \underline{y}_{\mathrm{ab}} \\ \underline{y}_{\mathrm{ba}} & \underline{y}_{\mathrm{bb}}\end{array}\right]=\left[\begin{array}{ll}\underline{z}_{\mathrm{aa}} & \underline{z}_{\mathrm{ab}} \\ \underline{z}_{\mathrm{ba}} & \underline{z}_{\mathrm{bb}}\end{array}\right]^{-1}$

Matrix (6) corresponds to the $\pi$-equivalent model shown in Figure 4. It follows from the definition of a nodal admittance matrix and the $\pi$-equivalent model that:

$\underline{y}_{\mathrm{ab}}=-\underline{Y}_{\mathrm{ab}}=-\frac{1}{\underline{Z}_{\mathrm{ab}}} ; \quad \underline{y}_{\mathrm{aa}}=\frac{1}{\underline{Z}_{\mathrm{a}}}+\frac{1}{\underline{Z}_{\mathrm{ab}}} ; \quad \underline{y}_{\mathrm{bb}}=\frac{1}{\underline{Z}_{\mathrm{b}}}+\frac{1}{\underline{Z}_{\mathrm{ab}}}$

where: $\underline{Z}_{\mathrm{a}}, \underline{Z}_{\mathrm{b}}, \underline{Z}_{\mathrm{ab}}$ are impedances of the $\pi$-equivalent model branches (Figure 4). From Equation (6) it follows that:

$\left[\begin{array}{cc}\underline{z}_{\mathrm{aa}} & \underline{z}_{\mathrm{ab}} \\ \underline{z}_{\mathrm{ba}} & \underline{z}_{\mathrm{bb}}\end{array}\right]=\underline{\mathbf{Y}}_{\pi}^{-1}=\frac{1}{\operatorname{det} \underline{\mathbf{Y}}_{\pi}}\left[\begin{array}{cc}\underline{y}_{\mathrm{bb}} & -\underline{y}_{\mathrm{ab}} \\ -\underline{y}_{\mathrm{ba}} & \underline{y}_{\mathrm{aa}}\end{array}\right]$

where: det $\underline{\mathbf{Y}}_{\pi}=\underline{y}_{\mathrm{aa}} \underline{y}_{\mathrm{bb}}-\underline{y}_{\mathrm{ab}} \underline{y}_{\mathrm{ba}}$. After having substituted the values resulting from Equation (7) to Equation (8) the following formulas can be obtained:
$\underline{Z}_{\mathrm{aa}}=\frac{\underline{Z}_{\mathrm{a}}\left(\underline{Z}_{\mathrm{b}}+\underline{Z}_{\mathrm{ab}}\right)}{\underline{Z}_{\mathrm{a}}+\underline{Z}_{\mathrm{b}}+\underline{Z}_{\mathrm{ab}}} ; \quad \underline{Z}_{\mathrm{bb}}=\frac{\underline{Z}_{\mathrm{b}}\left(\underline{Z}_{\mathrm{a}}+\underline{Z}_{\mathrm{ab}}\right)}{\underline{Z}_{\mathrm{a}}+\underline{Z}_{\mathrm{b}}+\underline{Z}_{\mathrm{ab}}} ;$

$\underline{z}_{\mathrm{ab}}=\underline{z}_{\mathrm{ba}}=\frac{\underline{Z}_{\mathrm{a}} \underline{Z}_{\mathrm{b}}}{\underline{Z}_{\mathrm{a}}+\underline{Z}_{\mathrm{b}}+\underline{Z}_{\mathrm{ab}}}$

Elements $\underline{z}_{\mathrm{aa}}$ and $\underline{z}_{\mathrm{bb}}$ correspond to impedances seen by the nodes a,b, respectively. This can be easily verified by calculating impedances seen by those nodes within the scheme of Figure 4.

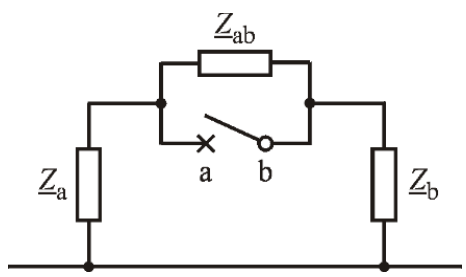

Figure $4 \pi$-equivalent model seen by the nodes a,b

The equivalent branch a-b and impedance $\underline{Z}_{\mathrm{ab}}$ are important for the $\pi$-equivalent model, because they represent the transmission network seen by the circuit breaker poles and considerably influences the initial switching current value.

\section{E. Thevenin's theorem and the nodal impedance method}

Equation (5) determines the switching current $\underline{I}_{\mathrm{ab}}$ as a function of $\underline{z}_{\mathrm{aa}}, \underline{z}_{\mathrm{bb}}, \underline{z}_{\mathrm{ab}}$, i.e. as a function of the nodal impedance matrix elements. This current can also be calculated using the Thevenin's theorem for the original network of Figure 1 or for the $\pi$-equivalent model of Figure 4. According to the Thevenin's theorem, when a circuit breaker gets closed the switching current can be expressed by the following formula:

$\underline{I}_{\mathrm{ab}}=\frac{\underline{V}_{\mathrm{ab}}}{\underline{Z}_{\mathrm{Th}}} \quad$ and $\quad I_{\mathrm{ab}}^{2}=\underline{I}_{\mathrm{ab}} \underline{I}_{\mathrm{ab}}^{*}=\frac{V_{\mathrm{ab}}^{2}}{Z_{\mathrm{Th}}^{2}}$

where: $\underline{V}_{\mathrm{ab}}$ is the voltage across the poles of a circuit breaker before it gets closed, $\underline{Z}_{\mathrm{Th}}$ is the Thevenin impedance seen by the nodes a,b.

Comparative analysis of Equations (10) and (5) indicates that the Thevenin impedance can be expressed the following way, with the use of nodal impedance matrix elements:

$\underline{Z}_{\mathrm{Th}}=\underline{z}_{\mathrm{aa}}+\underline{z}_{\mathrm{bb}}-2 \cdot \underline{z}_{\mathrm{ab}}$

where $\underline{z}_{\mathrm{aa}}, \underline{z}_{\mathrm{bb}}, \underline{z}_{\mathrm{ab}}$ are nodal impedance matrix elements. By substituting the values resulting from Equation (9) to Equation (11) the following can be obtained:

$\underline{Z}_{\mathrm{Th}}=\frac{\underline{Z}_{\mathrm{ab}}\left(\underline{Z}_{\mathrm{a}}+\underline{Z}_{\mathrm{b}}\right)}{\underline{Z}_{\mathrm{a}}+\underline{Z}_{\mathrm{b}}+\underline{Z}_{\mathrm{ab}}}=\frac{\underline{Z}_{\mathrm{a}}+\underline{Z}_{\mathrm{b}}}{\underline{\xi}}$

where 
$\underline{\xi}=1+\frac{\underline{Z}_{\mathrm{a}}+\underline{Z}_{\mathrm{b}}}{\underline{Z}_{\mathrm{ab}}}$

is a coefficient (generally a complex one) that represents the dependence of the Thevenin impedance on the impedance $\underline{Z}_{\mathrm{ab}}$ of the equivalent branch.

Equation (12) is consistent with the $\pi$-equivalent model of Figure 4, because when looking at the nodes a,b, the parallel connection of the impedance $\underline{Z}_{\mathrm{ab}}$ with the in series connected impedances $\underline{Z}_{\mathrm{a}}$ and $\underline{Z}_{\mathrm{b}}$ can be seen. This precisely gives the impedance given by Equation (12).

Concluding, it should be noted that the matrix considerations using a nodal impedance matrix lead to the same results as the Thevenin's theorem for the $\pi$-equivalent model (Figure 4).

\section{INITIAL SWITCHING CURRENT AS AN ANGLE FUNCTION}

Equations (5) and (10) determine a complex value of the initial switching current $\underline{I}_{\mathrm{ab}}$ within the reference frame common for the whole network. For the sake of analyzing the effect of inrush current caused by switching-on of a given network element it is not the complex value $\underline{I}_{\mathrm{ab}}$ that is important, but its absolute value $I_{\mathrm{ab}}=\left|\underline{I}_{\mathrm{ab}}\right|$.

Based on the phasor diagram shown in Figure 1, the voltage $\underline{V}_{\mathrm{ab}}$ that is present in Equations (5) and (10) can be calculated using the law of cosines. In this case the formula takes the following form:

$V_{\mathrm{ab}}^{2}=V_{\mathrm{a}}^{2}+V_{\mathrm{b}}^{2}-2 V_{\mathrm{a}} V_{\mathrm{b}} \cos \theta_{\mathrm{ab}}$

By dividing both sides of Equation (14) by $V_{\mathrm{b}}^{2}$ and introducing the coefficient $n=V_{\mathrm{a}} / V_{\mathrm{b}}$ the following can be obtained:

$\frac{V_{\mathrm{ab}}^{2}}{V_{\mathrm{b}}^{2}}=v^{2}-2 v \cos \theta_{\mathrm{ab}}+1$ or $V_{\mathrm{ab}}^{2}=V_{\mathrm{b}}^{2}\left(v^{2}-2 v \cos \theta_{\mathrm{ab}}+1\right)$

By substituting $V_{\mathrm{ab}}^{2}$ in Equation (10) with the value resulting from Equation (15), the following expression can be obtained:

$I_{\mathrm{ab}}=\frac{V_{\mathrm{b}}}{Z_{\mathrm{Th}}} \sqrt{\nu^{2}-2 v \cos \theta_{\mathrm{ab}}+1}=\frac{V_{\mathrm{b}}}{Z_{\mathrm{Th}}} \sqrt{\left(\nu-\cos \theta_{\mathrm{ab}}\right)^{2}+\sin ^{2} \theta_{\mathrm{ab}}}$

In the particular case, when there is no voltage difference $V_{\mathrm{a}}=V_{\mathrm{b}}=V$ and $v=1$, the following can be obtained from Equation (20):

$I_{\mathrm{ab}}=\frac{2 V}{Z_{\mathrm{Th}}} \sin \frac{\theta_{\mathrm{ab}}}{2} \quad$ for $\quad v=V_{\mathrm{a}} / V_{\mathrm{b}}=1$

because $\left(1-\cos \theta_{\mathrm{ab}}\right)=2 \sin ^{2}\left(\theta_{\mathrm{ab}} / 2\right)$.
It should be kept in mind that Equations (16) and (17) define only the AC component of the switching current. That component is complemented by the DC component (as in the short circuit case). It is also worth noting that (according to (12)) in the discussed equations the impedance $Z_{\mathrm{Th}}$ depends on the coefficient $\xi$.

\section{CHANGES IN THE GENERATOR CURRENTS AND POWER}

From the viewpoint of the above given criterion $\mathrm{C} 4$, a change in the real power of generators that is caused by switching-on of a given network element should be calculated [5, 13]. This change should satisfy the following condition:

$\Delta P_{\mathrm{G} 0+}=\operatorname{Re}\left(\underline{E}_{\mathrm{G}}^{\prime \prime} \cdot \Delta \underline{I}_{\mathrm{G} 0+}^{*}\right) \leq 0.5 P_{\mathrm{Gr}}$

A change in currents of the generators caused by the circuit breaker closing can be calculated with the use of Equation (1), which yields the following result:

$\underline{\boldsymbol{V}}_{\mathrm{B}}^{+}-\underline{\boldsymbol{V}}_{\mathrm{B}}=-\underline{\boldsymbol{Z}}_{\mathrm{Ba}} \underline{\boldsymbol{I}}_{\mathrm{ab}}+\underline{\boldsymbol{Z}}_{\mathrm{Bb}} \underline{I}_{\mathrm{ab}}$

or

$\underline{\boldsymbol{V}}_{\mathrm{B}}-\underline{\boldsymbol{V}}_{\mathrm{B}}^{+}=\left(\underline{\boldsymbol{Z}}_{\mathrm{Ba}}-\underline{\boldsymbol{Z}}_{\mathrm{Bb}}\right) \underline{I}_{\mathrm{ab}}$

and for an arbitrary $i$-th generator:

$\underline{V}_{i}-\underline{V}_{i}^{+}=\left(\underline{z}_{i \mathrm{a}}-\underline{z}_{i \mathrm{~b}}\right) \underline{I}_{\mathrm{ab}}$

Equation (21) defines the change in voltage at a generating bus caused by the circuit breaker closing. Hence, the change in currents of a generating unit (Figure 3) can be calculated using the Ohm's law:

$\Delta I_{\mathrm{G} i}=\underline{Y}_{\mathrm{G} i}\left(\underline{V}_{i}-\underline{V}_{i}^{+}\right)=\frac{\left(\underline{z}_{\mathrm{ia}}-\underline{z}_{i \mathrm{~b}}\right)}{\underline{\mathrm{Z}}_{\mathrm{G} i}} \underline{I}_{\mathrm{ab}}$

where $\underline{Z}_{\mathrm{G} i}=1 / \underline{\mathrm{Y}}_{\mathrm{G} i}$ is the impedance of a generator and its step-up transformer, while $\underline{z}_{i \mathrm{a}}$ and $\underline{z}_{i \mathrm{~b}}$ are elements of the nodal impedance matrix. Equation (22) describes a change in the generator current caused by closing of a given circuit breaker.

At calculating power change of a generator it should be remembered that any switching operation affects both the current and the voltage. The power change can be expressed by the following formula:

$\Delta S_{\mathrm{G} i}=S_{\mathrm{G} i}^{+}-S_{\mathrm{G} i}=\underline{V}_{i}^{+}\left(\underline{I}_{\mathrm{G} i}^{+}\right)^{*}-\underline{V}_{i}\left(\underline{I}_{\mathrm{G} i}\right)^{*}$

Further transformation of Equation (23) yields rather complex relations. It seems to be much easier to take advantage of the fact that the subtransient electromotive force of a generator does not undergo any changes. Considering the above, the generator power change can be calculated using the following formula: 


$$
\Delta S_{\mathrm{G} i}=\underline{E}_{\mathrm{G} i}^{\prime \prime} \cdot \Delta \underline{I}_{\mathrm{G} i}^{*}=\underline{E}_{\mathrm{G} i}^{\prime \prime} \cdot \frac{\left(\underline{z}_{i \mathrm{a}}^{*}-\underline{z}_{i \mathrm{~b}}^{*}\right)}{\underline{Z}_{\mathrm{G} i}^{*}} \underline{I}_{\mathrm{ab}}^{*}
$$

When using the above formula it should be kept in mind that the underlined symbols denote complex numbers within a common reference frame. By substituting Equation (5) it to (24) the following can be obtained:

$$
\Delta S_{\mathrm{G} i}=\frac{\underline{E}_{\mathrm{G} i}^{\prime \prime}}{\underline{Z}_{\mathrm{G} i}^{*}} \cdot \frac{\left(\underline{z}_{i \mathrm{a}}^{*}-\underline{z}_{i \mathrm{~b}}^{*}\right)}{\underline{z}_{\mathrm{aa}}^{*}+\underline{z}_{\mathrm{bb}}^{*}-2 \cdot \underline{z}_{\mathrm{ab}}^{*}} \cdot \underline{U}_{\mathrm{ab}}^{*} \text { and } \Delta P_{\mathrm{G} i}=\operatorname{Re} \Delta S_{\mathrm{G} i}
$$

where the lower case symbols $\underline{z}$ with relevant subscripts denote elements of the nodal impedance matrix.

The above given formulas make possible to calculate power changes $\mathrm{D} P_{\mathrm{G} i}$ for a given initial load flow in the network. From the viewpoint of synchro-check settings it is important to calculate the closing angle value $\theta_{\mathrm{ab}}$, at which the highest value of $\Delta P_{\mathrm{G} i}$, given by the formula (25), reaches the criterial value in the condition (18). In order to obtain such a value of the closing angle it is necessary to perform the following calculation steps:

(a) start with $\theta_{\mathrm{ab}}=\theta_{\mathrm{ab}}^{0}$, where superscript 0 denote the switching angle value in the initial system state (initial load flow),

(b) increase $\theta_{\mathrm{ab}}$ by a small value $\Delta \theta_{\mathrm{ab}}$,

(c) for new value of $\theta_{\mathrm{ab}}$ compute the complex values of $\underline{V}_{\mathrm{a}}$ , $\underline{\mathrm{b}}_{\mathrm{b}}$

(d) for given voltages $\underline{V}_{\mathrm{a}}, \underline{V}_{\mathrm{b}}$ solve the network equation to find new electromotive forces of all generators $\underline{E}_{\mathrm{G} i}^{\prime \prime}$,

(e) for the new system state calculate the sudden power changes given by Equation (25):

- $\quad$ if for all generators the sudden active power change is smaller than the criterial value in Condition (18), then return to $(b)$,

- $\quad$ if for the $i$-th generator the criterial value of the active power change is obtained then finish the calculations and accept the last value of $\theta_{\mathrm{ab}}$ as the maximal value.

When such a procedure is realized, the principal problem appears in the step (d), where for given voltages $\underline{V}_{\mathrm{a}}, \underline{V}_{\mathrm{b}}$ a new electromotive forces of all generators $\underline{E}_{\mathrm{G} i}$ must be determined. This problem can be solved in the following way. The system shown in Figure 1 can be described by the nodal admittance equation. By elimination of all load nodes [14] this equation can be reduced to the following equation:

$$
\left[\begin{array}{c}
\underline{\boldsymbol{I}}_{\mathrm{G}} \\
\hdashline \underline{0} \\
\underline{0}
\end{array}\right]=\left[\begin{array}{c:cc}
\underline{\boldsymbol{Y}}_{\mathrm{GG}} & \underline{\boldsymbol{Y}}_{\mathrm{Ga}} & \underline{\boldsymbol{Y}}_{\mathrm{Gb}} \\
\hdashline \underline{\boldsymbol{Y}}_{\mathrm{aG}} & \underline{y}_{\mathrm{aa}} & \underline{y}_{\mathrm{ab}} \\
\underline{\boldsymbol{Y}}_{\mathrm{bG}} & \underline{y}_{\mathrm{ba}} & \underline{y}_{\mathrm{bb}}
\end{array}\right]\left[\begin{array}{l}
\underline{\boldsymbol{E}}_{\mathrm{G}} \\
\hdashline \underline{V}_{\mathrm{a}} \\
\underline{V}_{\mathrm{b}}
\end{array}\right]
$$

where: $\underline{\boldsymbol{I}}_{\mathrm{G}}, \underline{\boldsymbol{E}}_{\mathrm{G}}$ are current vectors and electromotive forces of generators, $\underline{V}_{\mathrm{a}}, \underline{V}_{\mathrm{b}}$ are given voltages across the circuit breaker poles. It follows from the lower part of Equation (32) that:

$\underline{\boldsymbol{Y}}_{\mathrm{wG}} \Delta \underline{\boldsymbol{E}}_{\mathrm{G}}=-\underline{\boldsymbol{Y}}_{\mathrm{w}} \Delta \underline{\boldsymbol{V}}_{\mathrm{w}}$

where:

$\underline{\boldsymbol{Y}}_{\mathrm{wG}}=\left[\begin{array}{l}\underline{\boldsymbol{Y}}_{\mathrm{aG}} \\ \underline{\boldsymbol{Y}}_{\mathrm{bG}}\end{array}\right] ; \quad \underline{\boldsymbol{Y}}_{\mathrm{w}}=\left[\begin{array}{cc}y_{\mathrm{aa}} & \underline{y}_{\mathrm{ab}} \\ \underline{y}_{\mathrm{ba}} & \underline{y}_{\mathrm{bb}}\end{array}\right] ; \quad \Delta \underline{\boldsymbol{V}}_{\mathrm{w}}=\left[\begin{array}{c}\Delta \underline{V}_{\mathrm{a}} \\ \Delta \underline{V}_{\mathrm{b}}\end{array}\right]$

In Equation (33) the admittance matrix $\underline{\boldsymbol{Y}}_{\mathrm{w}}$ on the left side of $\underline{\boldsymbol{E}}_{\mathrm{G}}$ is rectangular. Therefore at given values of $\underline{V}_{\mathrm{a}}, \underline{V}_{\mathrm{b}}$ this equation has many solutions for $\underline{\boldsymbol{E}}_{\mathrm{G}}$, because there is more unknown values $\underline{E}_{\mathrm{G} i}^{\prime \prime}$ than equations. For such algebraic equation a unique solution exists in the sense of MoorePenrose [24-26]:

$\Delta \underline{\boldsymbol{E}}_{\mathrm{G}}=-\underline{\boldsymbol{Y}}_{\mathrm{wG}}^{* \mathrm{~T}}\left(\underline{\boldsymbol{Y}}_{\mathrm{wG}} \underline{\boldsymbol{Y}}_{\mathrm{wG}}^{* \mathrm{~T}}\right)^{-1} \underline{\boldsymbol{Y}}_{\mathrm{w}} \Delta \underline{\boldsymbol{V}}_{\mathrm{w}}$

where: $\underline{\boldsymbol{Y}}_{\mathrm{wG}}^{*_{\mathrm{T}}}\left(\underline{\boldsymbol{Y}}_{\mathrm{wG}} \underline{\boldsymbol{Y}}_{\mathrm{wG}}^{*_{\mathrm{T}}}\right)^{-1}$ is the Moore-Penrose pseudoinverse of the rectangular matrix $\underline{\boldsymbol{Y}}_{\mathrm{wG}}$. Solution given by Equation (29) minimizes the following function

$\left\|\Delta \underline{\boldsymbol{E}}_{\mathrm{G}}\right\|^{2}=\Delta \underline{\boldsymbol{E}}_{\mathrm{G}}^{* \mathrm{~T}} \Delta \underline{\boldsymbol{E}}_{\mathrm{G}}=\sum_{i=1}^{n}\left|\Delta E_{i}\right|^{2}$

This means that for a given angle $\theta_{\mathrm{ab}}$ and resulting voltages $\underline{V}_{\mathrm{a}}, \underline{V}_{\mathrm{b}}$ the above solution given bt Equation (29) provides minimal values of electromotive forces $\underline{\boldsymbol{E}}_{\mathrm{G}}$. From the technical point of view such a solution is reasonable and can be accepted for the considered simplified analysis of the switching operations.

\section{ERROR-ENCUMBERED CONCEPTS OFTEN USED IN PRACTICE}

According to Equation (12), the Thevenin impedance seen by the breaker poles depends on the coefficient $\underline{\xi}$ that is given by Equation (13). With the use of that coefficient Equation (10) can be rewritten the following way:

$\underline{I}_{\mathrm{ab}}=\frac{\underline{V}_{\mathrm{ab}}}{\underline{Z}_{\mathrm{Th}}}=\frac{\underline{V}_{\mathrm{ab}}}{\underline{Z}_{\mathrm{a}}+\underline{Z}_{\mathrm{b}}} \underline{\xi}$

In the particular case, when $\left|\underline{Z}_{\mathrm{ab}}\right|>>\left|\underline{Z}_{\mathrm{a}}+\underline{Z}_{\mathrm{b}}\right|$ and $\underline{\xi} \cong 1$ the switching current can be expressed by the following equation: 
$\underline{I}_{\mathrm{ab}} \cong \frac{\underline{V}_{\mathrm{ab}}}{\underline{Z}_{\mathrm{a}}+\underline{Z}_{\mathrm{b}}} \quad$ for $\quad \underline{\xi} \cong 1$

That simplification is equivalent to neglecting of the equivalent branch a-b (impedance $\underline{Z}_{\mathrm{ab}}$ ) in the $\pi$-equivalent model (Figure 4). Alas, in most cases of the real transmission networks, the equivalent branch a-b cannot be neglected, as the coefficient $\xi$ is much higher than unity. In practice, the $\xi$ values can considerably influence the value of the initial switching current $\underline{I}_{\mathrm{ab}}$ that is given by Equation (31). Generally, the simplified Equation (32) should not be used. Alas, in many publications this simplified equation is used and regarding the above considerations it can be deemed incorrect. Obviously, the branch a-b (impedance $\underline{Z}_{\mathrm{ab}}$ ) that is present in the $\pi$-equivalent model (Figure 4 ) could be neglected, if in the equation for the initial switching current calculation the voltage $\underline{V}_{\mathrm{ab}}$ were replaced by the difference of electromotive forces $\underline{E}_{\mathrm{a}}, \underline{E}_{\mathrm{b}}$ of the equivalent voltage sources connected to the branches $\underline{Z}_{\mathrm{a}}$ and $\underline{Z}_{\mathrm{b}}$, respectively. It is illustrated by Figure 5.

It follows from the diagram shown in Figure 5 that if before closing of the circuit breaker there is voltage $\underline{V}_{\mathrm{ab}}$ between nodes a,b, then the $\underline{V}_{\mathrm{ab}} / \underline{Z}_{\mathrm{ab}}$ current must flow through the $\underline{Z}_{\text {ab }}$ branch of the equivalent network. On the basis on that current and using the Kirchhoff 's law for the left and right sides of the Figure 5a diagram, the following values of the system source voltages can be calculated:

$\underline{E}_{\mathrm{a}}=\underline{V}_{\mathrm{a}}+\frac{\underline{V}_{\mathrm{ab}}}{\underline{\mathrm{Z}}_{\mathrm{ab}}} \underline{Z}_{\mathrm{a}} \quad$ and $\quad \underline{E}_{\mathrm{b}}=\underline{V}_{\mathrm{b}}-\frac{\underline{V}_{\mathrm{ab}}}{\underline{Z}_{\mathrm{ab}}} \underline{Z}_{\mathrm{b}}$

a)

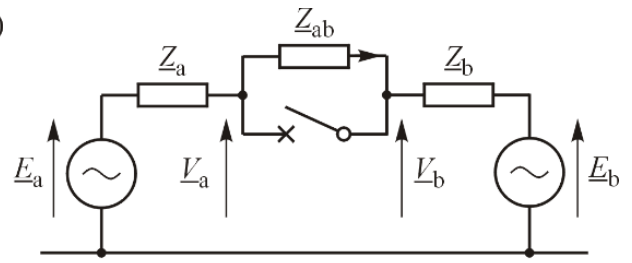

b)

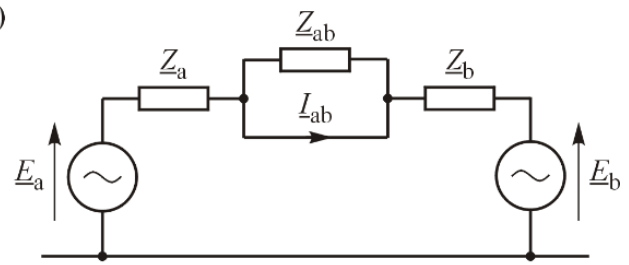

c)

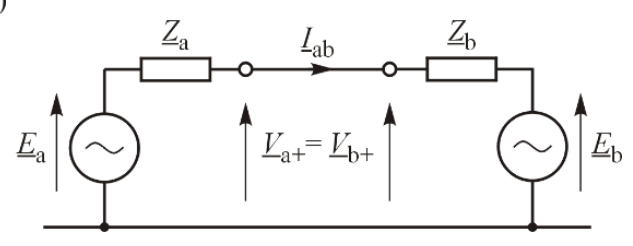

Figure 5 Illustration for the initial switching current calculations
The plus and minus signs in Equations (33) result from the current flow direction (Figure 5a). By performing both-sides subtraction on these equations the following can be obtained:

$\underline{E}_{\mathrm{a}}-\underline{E}_{\mathrm{b}}=\underline{V}_{\mathrm{a}}+\frac{\underline{V}_{\mathrm{ab}}}{\underline{Z}_{\mathrm{ab}}} \underline{Z}_{\mathrm{a}}-\underline{V}_{\mathrm{b}}+\frac{\underline{V}_{\mathrm{ab}}}{\underline{Z}_{\mathrm{ab}}} \underline{Z}_{\mathrm{b}}=\underline{V}_{\mathrm{ab}}+\frac{\underline{V}_{\mathrm{ab}}}{\underline{Z}_{\mathrm{ab}}}\left(\underline{Z}_{\mathrm{a}}+\underline{Z}_{\mathrm{b}}\right)$

where $\underline{V}_{\mathrm{ab}}=\underline{V}_{\mathrm{a}}-\underline{V}_{\mathrm{b}}$. Hence:

$\underline{E}_{\mathrm{a}}-\underline{E}_{\mathrm{b}}=\underline{V}_{\mathrm{ab}}\left(1+\frac{\underline{Z}_{\mathrm{a}}+\underline{Z}_{\mathrm{b}}}{\underline{Z}_{\mathrm{ab}}}\right)$

Thus, eventually the following can be obtained:

$\underline{E}_{\mathrm{a}}-\underline{E}_{\mathrm{b}}=\underline{\xi} \cdot \underline{V}_{\mathrm{ab}}$

where $\underline{\xi}$ is a coefficient given by Equation (13). Figure 6 presents a phasor diagram of voltages and electromotive forces and shows that the voltage difference can be much lower than the difference of electromotive forces.

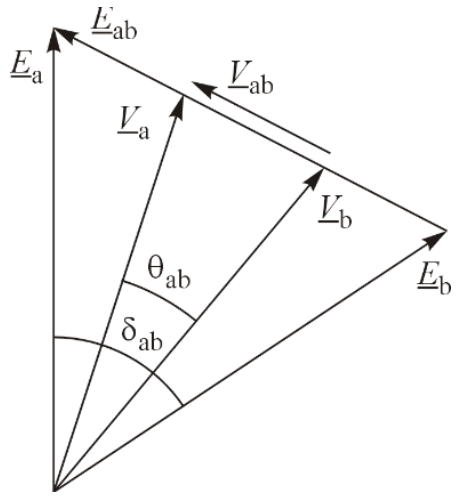

Figure 6 Phasor diagram of voltages and electromotive forces

Taking Equation (35) into account, the switching current $\underline{I}_{\mathrm{ab}}$ can be calculated on the basis of the diagram of Figure $5 c$, the following way:

$\underline{I}_{\mathrm{ab}}=\frac{\underline{E}_{\mathrm{a}}-\underline{E}_{\mathrm{b}}}{\underline{Z}_{\mathrm{a}}+\underline{Z}_{\mathrm{b}}}=\frac{\underline{V}_{\mathrm{ab}}}{\underline{Z}_{\mathrm{a}}+\underline{Z}_{\mathrm{b}}} \underline{\xi}$

Equation (36) is consistent with Equation (31) that has been earlier obtained with the use of the Thevenin's theorem. Obviously, for the case when $\underline{Z}_{\mathrm{ab}}=\infty$ there is $\underline{\xi}=1$ and $\underline{V}_{\mathrm{a}}=\underline{E}_{\mathrm{a}}$ and $\underline{V}_{\mathrm{b}}=\underline{E}_{\mathrm{b}}$ can be obtained. However, it is a particular case. In practice, when $\xi>1$ Equations (31) or (36) should be applied.

\section{THE ELABORATED COMPUTER SOFTWARE}

Co-authors of the presented paper have elaborated for the Polish Power System Operator (PSE S.A.) a computer software for performing short-circuit analyses (the SCC program) [27]. Obviously, as the software has been developed 
for an operator of a large-scale network, it applies well-known sparse matrix techniques [28-33] and object-oriented programming [30, 34, 35].

Researchers have been working on developing the sparse matrix techniques and algorithms since the seventies of the past century [32]. It is over 20 years now that the techniques can be used for a very fast determination of the nodal admittance matrix inverse that describes a power system. The proposed method applies those techniques as well as an original implementation using Object Oriented Programming in C++ [30]. Owing to that, the critical closing angle values can be very fast calculated (practically at once), although the modelled network systems are very extensive.

The SCC program conforms to the standard IEC 60909 [19].

On the basis of the sparse matrix procedures of the SCC program as well as of the above discussed method, the Synchrosoft software has been developed. In order to determine initial conditions and obtain transmission network data the SynchroSoft software cooperates with a typical load flow program in one package. Additionally, parameters of generating units can be loaded.

With respect to the Synchrosoft software, both the shortcircuit SCC program and the load-flow program are tools of auxiliary character. Both of them are used as the dynamic link libraries in specific steps of the discussed algorithm. The short-circuit software is meant to be used to determine parameters of the equivalent model (Figure 4). For that purpose, a network model in the form of a nodal admittance matrix is subjected to factorization and then for selected locations (points $a$ and $b$ ) values of self- and mutual impedances seen by the poles of an open circuit breaker (points $\mathrm{a}$ and $\mathrm{b}$ ) are determined using procedures of fastforward and fast-backward substitutions. Short-circuit parameters are not important for that case and are not determined. The task can be also realized with the use of other tools such as MATLAB. Practical reasons have decided over the application of the SCC program (Authors of the presented study have developed the SCC software).

The load-flow software is meant to determine the actual state of a network and the assumption is that it is an open-breaker state. The parameters of interest there are voltages (modules and angles) and nodal power. Values of those parameters make a starting point for the determination of the $\mathrm{C} 4$ criterion. In its current version, the SynchroSoft software is an interactive program that makes possible to step-by-step check the above discussed criteria. The software includes a typical Windows-like user interface. All program functions can be accessed from the levels of the menu, toolbar and interactive elements of forms displayed on the computer screen.

\section{EXAMPLES}

The below discussed results concern two power systems. The first one is a real large-scale power system and the other is a modified version of the CIGRE Test System.

\section{A. Small test system}

It is a modified version of the CIGRE Test System (Figure 7). Data of this system can be found in [36]. Voltage of that transmission network is of $220 \mathrm{kV}$. The modification consists in including a fragment of a distribution network of $110 \mathrm{kV}$ to the system. Table 2 sets up calculated allowed values for closing angles of the system lines.

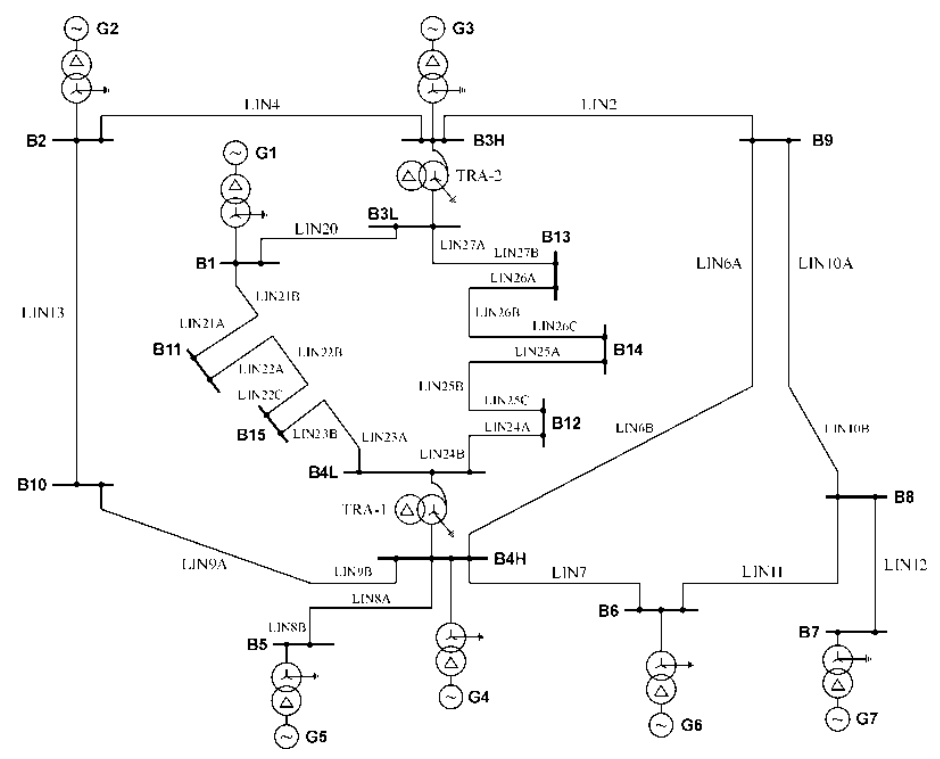

Figure 7 Modified CIGRE Test System

As can be seen in Table 2 in the discussed system it is the criterion $\mathrm{C} 4$ that is decisive for most of the cases. Criterion 2 is decisive only for two lines (one transmission line and one distribution line). It should be noted that for most of the lines the obtained allowed closing angle values are higher than $40^{\circ}$. There is only one case (line LIN20), where the obtained value is as low as of about $20^{\circ}$.

As in the case of the real large-scale system, calculation results obtained for the discussed test system have also not shown any justification for considering the recommendation to constrain the closing angle value down to $20^{\circ}$ to be a rule for the $220 \mathrm{kV}$ and $110 \mathrm{kV}$ networks.

TABLE 2

ALLOWED VALUES OF THE CLOSING ANGLE

\begin{tabular}{|c|c|c|c|c|c|}
\hline Line & \multicolumn{2}{|c|}{ Ends } & $V_{\mathrm{n}}[\mathrm{kV}]$ & Angle & Criterion \\
\hline LIN2 & $\mathrm{B} 3 \mathrm{H}$ & B9 & \multirow{8}{*}{$220 \mathrm{kV}$} & $39.5^{\circ}$ & $\mathrm{C} 4$ \\
\hline LIN4 & $\mathrm{B} 3 \mathrm{H}$ & B2 & & $35.3^{\circ}$ & $\mathrm{C} 4$ \\
\hline LIN6 & B9 & B4H & & $40.3^{\circ}$ & $\mathrm{C} 2$ \\
\hline LIN7 & B4H & B6 & & $42.3^{\circ}$ & $\mathrm{C} 4$ \\
\hline LIN9 & B4H & B10 & & $53.8^{\circ}$ & $\mathrm{C} 4$ \\
\hline LIN10 & B9 & B8 & & $>90^{\circ}$ & none \\
\hline LIN11 & B8 & B6 & & $33.2^{\circ}$ & $\mathrm{C} 4$ \\
\hline LIN13 & $\mathrm{B} 10$ & $\mathrm{~B} 2$ & & $51.1^{\circ}$ & $\mathrm{C} 4$ \\
\hline LIN20 & B3L & B1 & \multirow{7}{*}{$110 \mathrm{kV}$} & $23.4^{\circ}$ & $\mathrm{C} 4$ \\
\hline LIN21 & B1 & B11 & & $45.3^{\circ}$ & $\mathrm{C} 4$ \\
\hline LIN22 & B11 & B15 & & $54.1^{\circ}$ & $\mathrm{C} 2$ \\
\hline LIN24 & $\mathrm{B} 4 \mathrm{~L}$ & B12 & & $41.9^{\circ}$ & $\mathrm{C} 4$ \\
\hline LIN25 & B12 & B14 & & $40.5^{\circ}$ & $\mathrm{C} 4$ \\
\hline LIN26 & B14 & B13 & & $82.5^{\circ}$ & $\mathrm{C} 4$ \\
\hline LIN27 & B13 & B3L & & $62^{\circ}$ & $\mathrm{C} 4$ \\
\hline
\end{tabular}




\section{B. Large-scale real power system}

In order to show the importance of the equivalent branch a-b (Figure 4) and the coefficient $\underline{\xi}$ (Equations (13) (14)) an analysis has been performed for a real power system with a transmission network system of $400 \mathrm{kV}$ and $220 \mathrm{kV}$ that includes 664 lines and transformers and a distribution network $110 \mathrm{kV}$ including 3933 lines and transformers. Coefficient $\underline{\xi}$

has been calculated for all those network elements. Statistical results are illustrated by the curve shown in Figure 8.

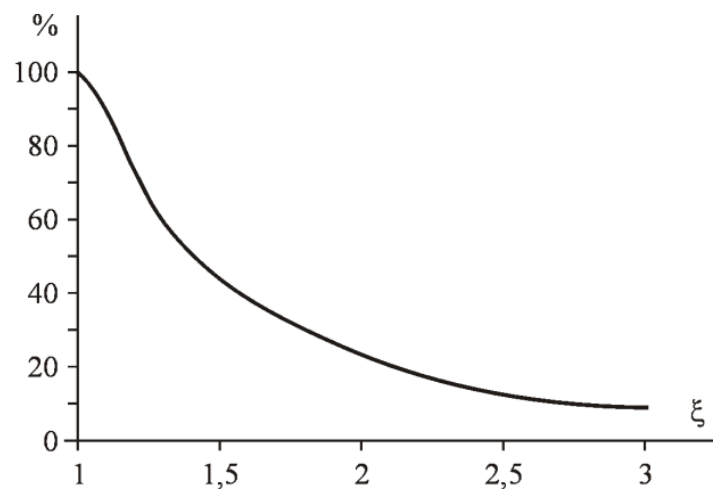

Figure 8 Statistical distribution of the $\xi$ value for an example transmission network

For a given value $\xi$ the diagram shown in Figure 8 determines a percent number of network elements, for which the coefficients $\xi$ are higher than the given value. For instance, $\xi \geq 1.5$ has been obtained for $45 \%$ of the network elements; $\xi \geq 2.0$ for $25 \%$ of the elements; and $\xi \geq 3.0$ for $10 \%$ of them. This means that, when the branch $a-b$ is neglected in the $\pi$-equivalent model and Equation (33) is used instead of Equation (32), for $45 \%$ of the network elements the calculated value of the switching current $\underline{I}_{\mathrm{ab}}$ is 1.5 times smaller than the proper value, for $25 \%$ of the network elements - it is 2 times smaller, and for $10 \%$ of the network elements - it is even 3 times smaller. These are obviously absolutely unacceptable errors.

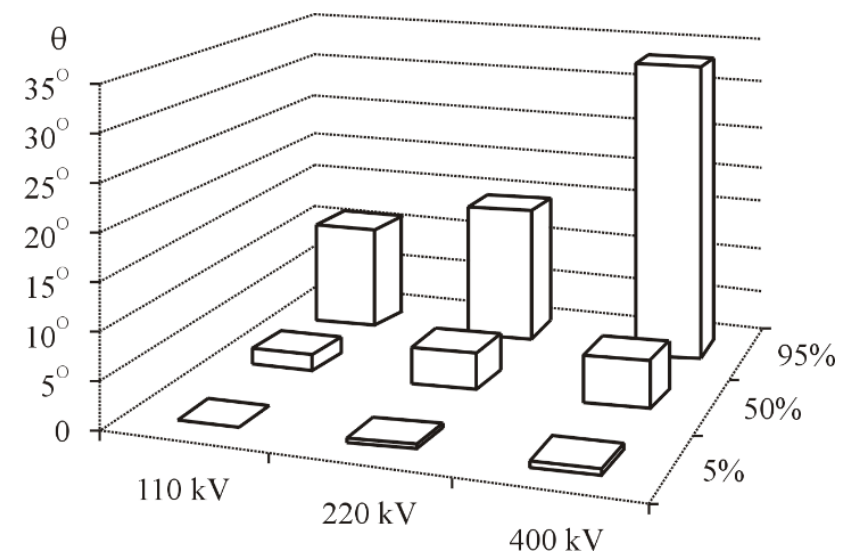

Figure 9 Percentiles of the closing angles for outages of a single transmission line

Percentiles of the closing angles (also referred to as standing phase angles [21]) are shown in Figure 9. The highest values (approx. $30^{\circ}$ ) concern the transmission network of $400 \mathrm{kV}$, lower values (approx. $20^{\circ}$ ) are for the transmission network of $220 \mathrm{kV}$ and the lowest ones (approx. 15 ${ }^{\circ}$ - for the distribution network of $110 \mathrm{kV}$.

Determination of the criteria that are the most restrictive and decisive for the synchro-check settings depends on parameters of the switched element and loading conditions in the power system. In practice, it usually is C3 as well as C1 that are nonrestrictive. For short transmission lines (especially the ones located in the vicinity of large generating units driven by steam turbines), the $\mathrm{C} 4$ criterion is decisive, while for very long transmission lines it can be the $\mathrm{C} 2$ criterion (distance protection). It is illustrated by Table 3, where the lowest allowed closing angle values calculated for the considered power system are given.

TABLE 3

LOWEST ALLOWED VALUES OF THE CLOSING ANGLE

\begin{tabular}{|c|c|c|c|c|c|c|c|}
\hline \multirow{2}{*}{\multicolumn{2}{|c|}{ Type of a line }} & \multicolumn{2}{|c|}{$400 \mathrm{kV}$} & \multicolumn{2}{|c|}{$220 \mathrm{kV}$} & \multicolumn{2}{|c|}{$110 \mathrm{kV}$} \\
\hline & & ang & criterion & ang & criterion & ang & criterion \\
\hline \multirow[b]{2}{*}{ long } & $\begin{array}{l}\text { close to } \\
\text { generating } \\
\text { stations }\end{array}$ & $78.7^{\circ}$ & $\mathrm{C} 2$ & $66.7^{\circ}$ & $\mathrm{C} 2$ & $27.8^{\circ}$ & $\mathrm{C} 4$ \\
\hline & $\begin{array}{l}\text { far from } \\
\text { generating } \\
\text { stations }\end{array}$ & $61.4^{\circ}$ & $\mathrm{C} 2$ & $54.5^{\circ}$ & $\mathrm{C} 2$ & $46.1^{\circ}$ & $\mathrm{C} 2$ \\
\hline \multirow[b]{2}{*}{ short } & $\begin{array}{l}\text { close to } \\
\text { generating } \\
\text { stations }\end{array}$ & $59.0^{\circ}$ & $\mathrm{C} 4$ & $43.9^{\circ}$ & $\mathrm{C} 4$ & $>90^{\circ}$ & none \\
\hline & $\begin{array}{l}\text { far from } \\
\text { generating } \\
\text { stations }\end{array}$ & $91.0^{\circ}$ & $\mathrm{C} 4$ & $25.0^{\circ}$ & $\mathrm{C} 2$ & $24.0^{\circ}$ & $\mathrm{C} 4$ \\
\hline
\end{tabular}

Calculations performed for the considered real power system have shown no justification for considering the recommended constraint of $20^{\circ}$ on the closing angle value to be a rule for the $400 \mathrm{kV}$ and $220 \mathrm{kV}$ networks. For those networks of the considered power system the allowed closing angle value of $45^{\circ}$ can be quite safely assumed.

\section{CONCLUSIONS}

Optimal setting of the synchro-check parameters requires an efficient method for calculating the initial switching current and changes in the real power of the generating units resulting from switching-on of a given network element. A new calculation method based on the nodal impedance matrix has been proposed. The advantage of this method is that the suitable impedance matrix is available in the short-circuit computer programs commonly used for the short-circuit analyses and that such computer programs with an adequate extension done can also be applied to the analysis of the switching operations.

It has been also shown that a simplified computation of the initial switching current with neglecting the series branch in the $\pi$-equivalent model can be encumbered with significant errors. That is why it is recommended to use the proposed method based on the impedance matrix.

Analyses performed for the Polish transmission network system of $400 \mathrm{kV}$ and $220 \mathrm{kV}$ and for the Modified CIGRE 
Test System have shown no justification for considering the recommended constraint of $20^{\circ}$ on the closing angle value as a rule for the $400 \mathrm{kV}$ and $220 \mathrm{kV}$ networks. For most of the analyzed cases, closing angles of $(45 \div 60)^{\circ}$ have been allowed. This statement refers specifically to the system considered in this paper, which not necessarily makes it a general rule. For substations located close to huge thermal power plants these angle values can be too high.

From the viewpoint of power system operators, it would be advantageous if the synchro-check devices had a few sets of setting values to be selected in hard loading conditions that pose a hazard of the cascade cut-out and blackout occurrence. Manufacturers of synchro-check devices should take the above into consideration and provide an option of setting at least two-parameter sets with one of them to be selected in an emergency state, when a hazard of the power system blackout occurrence is greater than the risk of reducing the life of individual elements of the system.

\section{ACKNOWLEDGMENT}

The presented research has been realized within the framework of the project No 4/WEiIPL/IF/2010/RB/TK funded by the Polish Transmission Network Operator (PSE S.A), Warsaw, Poland.

\section{REFERENCES}

[1] A. Greenwood, Electrical transients in power systems, 2nd ed. New York [u.a.]: Wiley, 1991.

[2] J. Machowski, P. Kacejko, and P. Miller, "Criteria for closing of transmission network ring structures," Przeglad Elektrotechniczny (Electrical Review), no. 10, pp. 272-280, 2011.

[3] Working Group A3.11, Guide for application of IEC 62271-100 and 62271-1. CIGRE Report No 304

[4] V. Cook, Analysis of distance protection. Letchworth, Hertfordshire, England, New York: Research Studies Press; Wiley, 1985.

[5] D. Reimert, Protective relaying for power generation systems. Boca Raton, FL: CRC/Taylor \& Francis, 2006.

[6] K. Läge and D. Lambrecht, "Die Auswirkung dreipoliger Netzkurz-schlüsse mit Kurzschlussfortschaltung auf die mechanische Beansprachung von Turbosätzen," ETZ-A, vol. 95, no. 10, 1974.

[7] B. Kulicke and A. Webs, "Elektromechanisches Verhalten von Turbosetzen bei Kurzschlüssen in Kraftwerksnähe," ETZ-A, vol. 96, no. 4, 1975.

[8] P. Bölder, T. Kulig, and D. Lambrecht, "Beurteilung der Torsionsbeanspruchung in den Wellen von Turbosätzen bei wiederholt auftrenden Störungen im Laufe der Betriebszeit," ETZ-A, vol. 96, no. 4, 1975.

[9] J. S. Joyce, T. Kulig, and D. Lambrecht, "Torsional Fatigue of Turbine-Generator Shafts Caused by Different Electrical System Faults and Switching Operations," IEEE Trans. on Power Apparatus and Syst, vol. 97, no. 5, pp. 1965-1977, 1978.

[10] R. Dunlop, Horowitz S.H, Joyce J.S, and D. Lambrecht, Eds, Torsional oscillations and fatique of steam turbine - generator shafts caused by system disturbances and switching events, 1980.

[11] D. Lambrecht, T. Kulig, W. Berchtold, J. Hoorn, and H. Fick, Eds, Evaluation of the torsional impact of accumulated failure combinations on turbine generator shfts as basis of design guidelines, 1984.

[12] "Effects of Switching Network Disturbances on Turbine-Generator Shaft Systems," IEEE Trans. on Power Apparatus and Syst, vol. PAS-101, no. 9, pp. 3151-3157, 1982.

[13] "IEEE Screening Guide for Planned Steady-State Switching Operations to Minimize Harmful Effects on Steam Turbine-Generators," IEEE Trans. on Power Apparatus and Syst, vol. 99, no. 4, pp. 1519-1521, 1980.

[14] J. Machowski, J. W. Bialek, and J. R. Bumby, Power system dynamics: Stability and control, 2 nd ed. Chichester, U.K: Wiley, 2008.

[15] M.J. Thompson, Ed, Fundamentals and advancements in generator synchronizing systems, 2012.

[16] L. Oprea, V. Popescu, and W. Sattinger, Eds, Coordinated synchronism check settings for optimal use of critical transmission network corridors, 2007.

[17] Mid Atlantic Area Council (MAAC), Protective Relaying Philosophy and Design Standards. Available: https://www.rfirst.org/standards/Documents/MAAC\%2 0Documents\%20082709.pdf.

[18] S. Wunderlich, M. Adibi, R. Fischl, and C. Nwankpa, "An approach to standing phase angle reduction," IEEE Trans. Power Syst, vol. 9, no. 1, pp. 470-478, 1994.

[19] Short-circuit currents in three-phase A.C. systems. International Standard IEC 60909. Available: http://webstore.iec.ch/preview/info_iec609090\%7Bed1.0\%7Den_d.pdf.

[20] "Automatic Reclosing of Transmission Lines An IEEE Power System Relaying Committee Report," IEEE Power Eng. Rev, vol. 4, no. 2, pp. 21-22, 1984.

[21] D. Hazarika and A. Sinha, "Standing phase angle reduction for power system restoration," IEE Proc, Gener. Transm. Distrib, vol. 145, no. 1, pp. 82-88, 1998.

[22] A. Bartylak, Ed, The ARC Settings Requirements on the ESCOM Transmission System, 2011.

[23] UCTE, Final Report of the Investigation Committee on the 28 September 2003 Blackout in Italy.

[24] E. H. Moore, "On the reciprocal of the general algebraic matrix," Bulletin of the American Mathematical Society, no. 26 (9), pp. 394-395, 1920.

[25] R. Penrose, "A generalized inverse for matrices," Mathematical Proceedings of the Cambridge Philosophical Society, vol. 51, no. 03, pp. 406-413, 1955.

[26] R. Penrose and J. Todd, "On best approximate solutions of linear matrix equations," Mathematical Proceedings of the Cambridge Philosophical Society, vol. 52, no. 01, pp. 17-19, 1956.

[27] P. Kacejko and P. Miller, "Short-Circuit analysis of power grid with consideration of wind farms as controlled circuit sources," Acta Energetica, no. 4, pp. 49-56, 2011. 
[28] I. S. Duff, A. M. Erisman, and J. K. Reid, Direct methods for sparse matrices, 1997th ed. Oxford: Clarendon Press, 1997.

[29] R. P. Tewarson, Sparse matrices. New York, 1973.

[30] P. Kacejko, P. Miller, and T. J. Hammons, “ObjectOriented Approach to the Enhancement of Energy Management Systems Software Engineering," Electric Machines and Power Systems, vol. 28, pp. 193-202, 2000.

[31] A. Brameller, R. N. Allan, and Y. M. Hamam, Sparsity: Its practical application to systems analysis. London, New York: Pitman, 1976.

[32] I. S. Duff, "A survey of sparse matrix research," Proc. IEEE, vol. 65, no. 4, pp. 500-535, 1977.

[33] J. R. Gilbert, C. Moler, and R. Schreiber, Sparse matrices in MATLAB: Design and implementation, 1991.

[34] T. J. Hammons, A. Flett, and P. Kacejko, "Computerprograms for fault studies using symmetrical components in undergraduate and postgraduate teaching," Electric Machines and Power Systems, vol. 20, no. 5, pp. 425-444, 1992.

[35] P. Kacejko, P. Miller, and M. Wancerz, Eds, Object Oriented Approach to the Enhancement of Energy Management Systems Software Engineering, 1997.

[36] Modified Cigre Test System. Available: http://www.ien.pw.edu.pl/EAZ/_pdf/CIGRE_Modified _Test_System.pdf.

\section{Jan Machowski}

Warsaw University of Technology

e-mail: jan.machowski@ien.pw.edu.pl

Obtained his M.Sc. (1974) and Ph.D. (1978) degrees in Electrical Engineering from Warsaw University of Technology (Poland), where he has been working since 1978. In 1989-1992 he was a visiting professor at Kaiserslautern University (Germany). Since 1993 his is a full professor at Warsaw University of Technology. His research interests are in power systems and especially power system analysis, control and protection. He is the co-author of the textbook "Power System Dynamics. Stability and Control" published by J. Wiley in 2008.

\section{Piotr Kacejko}

Lublin University of Technology

e-mail: p.kacejko@pollub.pl

Head of the Department of Electrical Grids and Protections of Lublin University of Technology. The author was awarded his post-doctoral degree at the Faculty of Electrical Engineering of Warsaw University of Technology in 1999, and the title of professor in 2006. He specializes in power system analysis, especially in emergency conditions, and numerical methods of analysis.

\section{Piotr Miller}

Lublin University of Technology

e-mail: p.miller@pollub.pl

Graduated from the Electrical Engineering Faculty of Lublin University of Technology. Currently an assistant professor at the Department of Electrical Grids and Protections. He specializes in numerical methods and software used in the analysis of power system emergencies. The chief developer of SCC computer program SCC commonly used by operators in the commercial power sector and by designers. 